\title{
A Facile Synthesis of $\alpha-\mathrm{Fe}_{2} \mathrm{O}_{3} /$ Carbon Nanotubes and Their Photocatalytic and Electrochemical Sensing Performances
}

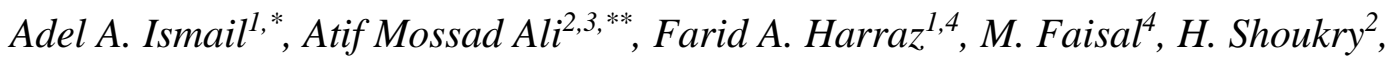 \\ A.E. Al-Salami ${ }^{2}$ \\ ${ }^{1}$ Nanomaterials and Nanotechnology Department, Central Metallurgical Research and Development \\ Institute (CMRDI), P.O. 87 Helwan, Cairo 11421, Egypt \\ ${ }^{2}$ Department of Physics, Faculty of Science, King Khalid University, Abha, Saudi Arabia \\ ${ }^{3}$ Department of Physics, Faculty of Science, Assiut University, Assiut, Egypt \\ ${ }^{4}$ Promising Centre for Sensors and Electronic Devices, Advanced Materials and Nano-Research \\ Centre, Najran University, Najran, Saudi Arabia. \\ *E. mail: adelali141@yahoo.com, atifali@kku.edu.sa
}

doi: $10.20964 / 2019.01 .09$

Received: 5 October 2018 / Accepted: 31 October 2018 / Published: 30 November 2018

\begin{abstract}
This study reports a simple process for synthesizing efficient photocatalyst based on mesoporous carbon nanotubes (CNT)- $\alpha-\mathrm{Fe}_{2} \mathrm{O}_{3}$ nanohybrids at different CNT contents as well as their photocatalytic performance under visible light illumination. TEM image of CNT- $\alpha-\mathrm{Fe}_{2} \mathrm{O}_{3}$ nanohybrid exhibited that $\mathrm{Fe}_{2} \mathrm{O}_{3}$ nanoparticles are well distributed homogeneously in the CNT surface with size of $<10 \mathrm{~nm}$ and lattice fringes were obviously assigned with a spacing of $0.252 \mathrm{~nm}$, conforming to the (110) planes of $\alpha-\mathrm{Fe}_{2} \mathrm{O}_{3}$. The prepared mesoporous $\mathrm{CNT}-\alpha-\mathrm{Fe}_{2} \mathrm{O}_{3}$ nanohybrids act as efficient and reusable photocatalysts for the photocatalytic oxidation of Bismarck Brown R (BBR) Dye. The total removal efficiency was boosted from 83 to $98 \%$ with the increase of CNT contents from 0 to $50 \%$. The decolorization rate of BBR dye over $50 \%$ CNT- $\alpha-\mathrm{Fe}_{2} \mathrm{O}_{3}$ nanohybrid is greater by almost 35 times than that of the pure mesoporous $\mathrm{Fe}_{2} \mathrm{O}_{3}$. The superior photocatalytic performance of mesoporous CNT- $\alpha$ $\mathrm{Fe}_{2} \mathrm{O}_{3}$ nanohybrids over mesoporous $\alpha-\mathrm{Fe}_{2} \mathrm{O}_{3}$ is mainly owing to the synergistic effect and effective retard electron-hole recombination at the $\mathrm{CNT} / \mathrm{Fe}_{2} \mathrm{O}_{3}$ interfaces. The high photocatalytic performance and easily recyclable of CNT- $\alpha-\mathrm{Fe}_{2} \mathrm{O}_{3}$ nanohybrids come to be promising photocatalyst and adsorbent for industrial and domestic wastewater treatment. Furthermore, the optimal sample of $50 \%$ CNT- $\alpha$ $\mathrm{Fe}_{2} \mathrm{O}_{3}$ modified glassy carbon electrode (GCE) was examined to the electrochemical detection and determination of phenyl-hydrazine. The sensor electrode exhibited outstanding sensitivity of 1081 $\mu \mathrm{AmM}^{-1} \mathrm{~cm}^{-2}$ within a linear dynamic range from $10 \mu \mathrm{M}$ to $1 \mathrm{mM}$ with a correlation coefficient $\mathrm{R}^{2}=$ 0.9995 and a low limit of detection (LOD) $6.25 \mu \mathrm{M}$.
\end{abstract}

Keywords: CNT- $\alpha-\mathrm{Fe}_{2} \mathrm{O}_{3}$; Nanohybrids; Electrochemical sensing; Photocatalyst; Photodegradation 


\section{FULL TEXT}

(C) 2019 The Authors. Published by ESG (www.electrochemsci.org). This article is an open access article distributed under the terms and conditions of the Creative Commons Attribution license (http://creativecommons.org/licenses/by/4.0/). 